\title{
Research on characteristic town's industrial layout - Based on ShenYang general Aviation land use planning xiaofan Zhao ${ }^{1, \mathrm{a}}$, yannin $\mathrm{Ji}^{2, \mathrm{~b},{ }^{*}}$
}

${ }^{1}$ School of design and art ,Shenyang aerospace university, Shenyang, Liaoning China

2 Shenyang Urban construction university, Shenyang, Liaoning China

$$
\text { zhaoxiaofan7724@163.com }
$$

Corresponding author Zhao Xiaofan

\begin{abstract}
Keywords: characteristic town, general aviation, industrial planning
\end{abstract}
\begin{abstract}
The concept of general Aviation town is based on the characteristic town. Based on the core business and infrastructure of navigation, it gathers diverse functions such as production, residence, business, leisure, and tourism. The characteristic town should rely on the unique resources of the local area. Town planning is combined with the cultivation of characteristic industries to integrate multidimensional development elements. The combination of General Aviation and characteristic towns is not only the demand of industrial development, but also the driving force of regional economy. Whether it is from the industrial park to the characteristic town, from the key town to the characteristic town and even the pastoral complex, the future regions should combine the local economic, cultural and industrial characteristics to develop rather than blindly imitate. Taking Shenyang general aviation industrial land use planning as an example, the paper discusses the industrial layout pattern and strategy of characteristic town.
\end{abstract}

\section{特色小镇的产业布局研究以沈阳通用航空产业基地规划为例 \\ 赵晓凡 ${ }^{1, a}$, 吉燕宁2,b, ${ }^{*}$ \\ 1沈阳航空航天大学设计艺术学院, 沈阳, 辽宁, 中国 \\ 2沈阳城市建设学院, 沈阳, 辽宁, 中国 \\ zhaoxiaofan7724@163.com \\ 通讯作者: 赵晓凡}

关键词: 特色小镇; 通用航空; 产业基地规划

中文摘要. 通航小镇概念建立在特色小镇概念的基础上, 基于通航核心业务与基础设施, 聚 集生产、居住、商务、休闲、旅游等多样化功能, 特色小镇应以当地独具特色的资源为依托, 将城镇规划与特色产业培育结合起来, 融合多维发展元素。通用航空与特色小镇的结合, 既 是产业发展的需求, 也是区域经济转型的推动力。不论是从产业园区到特色小镇, 从重点镇 到特色小镇乃至田园综合体, 未来各地区都应当结合当地的经济、文化以及产业特色进行发 展, 而非盲目模仿。本文以沈阳通用航空产业基地规划为例, 探讨特色小镇的产业布局模式 与策略。

\section{1. 引言}


自2016年2月我国发布《关于深入推进新型城镇化建设的若干意见》后，特色小镇作为经 济新常态下的概念快速进入大众视野。2016年8月我国住建部、发改委、财政部联合下发文件

《关于开展特色小镇培育工作的通知》，正式拉开了新型城镇化快速发展的序幕。在全国性 的 “小镇东风”下, 特色小镇已成为当下热门领域的代名词。截至目前为止, 住建部共公布 了 403 个特色小镇名单, 引起社会高度重视。沈阳市法库县十间房镇是公布的2017年国家级特 色小镇之一，2013年以来，小镇先后获批全国最具投资价值通用航空产业集聚区、辽宁省首 个通用航空产业基地、全国首批国家级航空飞行营地、辽宁省航空体育产业示范镇、国家级 通用航空产业综合示范区。

\section{2 通航小镇基地规划范畴与目标}

通航小镇是指在相当大的地域范围内, 基于通用机场、空域与土地基础, 以航空体验功 能为主导, 以旅游项目、居住房产和休闲地产为核心, 以房产收益为支撑、以高品质功能齐 全的航空服务为根本进行土地综合开发而形成的品质较高的通用航空产业综合体。

\section{1通航小镇基地规划实施策略与产业发展模式}

\subsection{1通航产业发展模式研究}

通用航空是国家战略性新兴产业, 我国通用航空产业处于起步阶段, 全国通航产业发展 的实践探索时间较短, 许多发展模式与经验尚需要广泛的借鉴于欧美发达国家。在未来通航 产业发展过程中, 需要结合我国国情, 落实通航发展政策, 培育通航市场, 促进通航制造与 运营服务协调发展，探索出一条适合于我国特色的通用航空产业发展模式。

2.1.2产业发展与生态环境的协调

生态环境是经济社会发展与文明兴衰的基本载体。经济社会发展必须建立在资源得到高 效循环利用, 生态环境受到严格保护的基础上。对于山水相依、绿景环绕的风水宝地, 城镇 的建设与开发势必会影响原有的生态格局。如何科学布局生态空间、生活空间和生产建设空 间, 促进经济社会与生态环境协调发展, 使得通用航空产业基地的发展与生态环境和谐共处、 相得益彰。

2.1.3产业规划与城镇规划的结合

产业规划是对当地产业发展定位、产业体系、产业结构、产业链、空间布局等进行整体 布置和规划。产业规划与城镇规划在发展过程中是一种双向互促关系, 互为先导。城镇规划 引导产业的空间布局,影响着产业发展的方向,并进而对产业规划形成较大的推动作用。产业发 展引起城镇功能的变化, 对城镇规划提出新的要求, 促进城镇功能布局的调整。将产业发展的内 核落实到城镇规划中, 实现产业布局与城镇功能的协调, 通过推动产业发展来带动本地经济 的快速提升。

\section{2国内外通航产业现状}

从供给的角度来看，产业是指具有类似生产技术、生产过程、生产工艺等特征的物质生 产活动或者类似经济性质的服务活动的总和; 从需求的角度来看, 产业是指同类或者具有替 代和竞争关系的产品或服务的集合。供给体系：以通用航空运营企业为核心，包括通用航空 器研发与制造、通用航空机场建设与运营、通用航空人才培养与培训、通用航空服务与综合 保障等庞大的产业体系。需求体系: 民用航空活动中除公共运输之外的所有对航空活动的需 求, 包括工业作业、农林作业、公益航空、教育培训、文化体育、公务飞行、私人飞行等范 围广泛的市场体系。据《中国通用航空发展报告2016-2017》显示: 2016年, 全国通用航空行 业完成通用航空生产作业飞行 76.47万小时，比上年降低 $1.8 \%$ 。其中，工业航空作业完成8.29 万小时, 占作业总量的 $10.8 \%$; 农林业航空作业完成 5.10 万小时, 占作业总量的 $6.7 \%$; 其他通 用航空飞行63.08万小时。（如图1） 

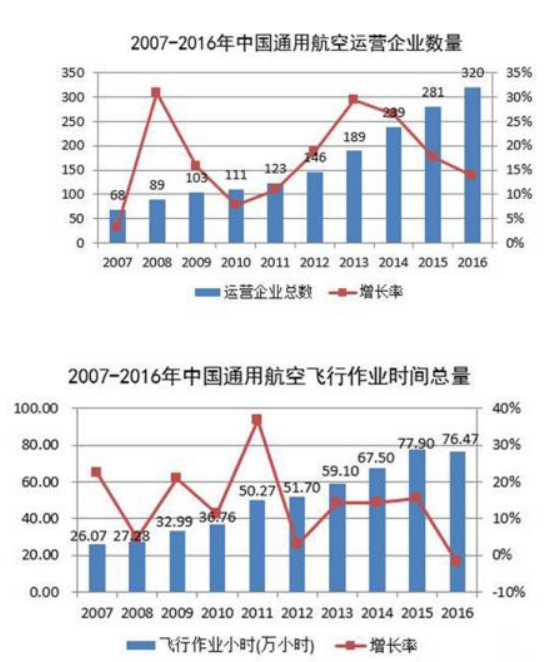
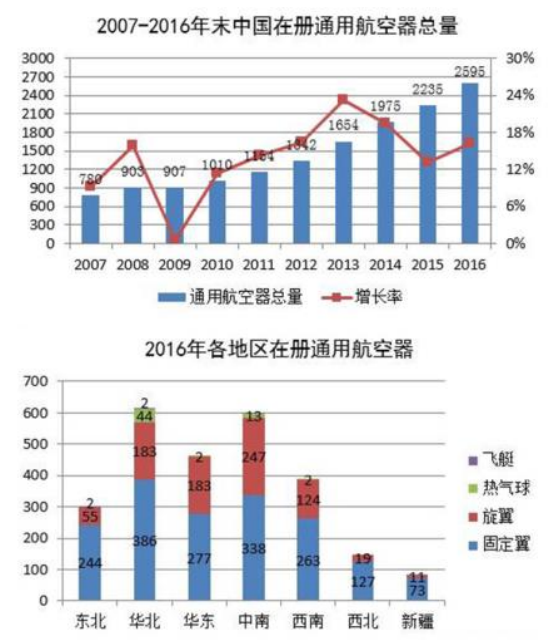

2016年中国通用航空作业时间分布（万小时）

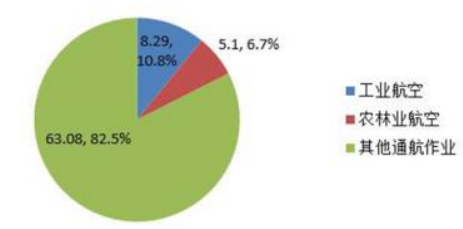

2016年实际作业的通用航空公司地区分布
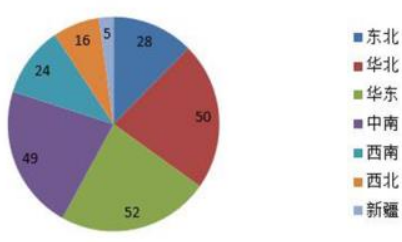

图1 国内通航 来源: 中国通用航空发展报告2016-2017

\section{3 国外通航产业案例借鉴}

表一 美国威奇塔机场产业格局

\begin{tabular}{|c|c|c|c|c|}
\hline $\begin{array}{l}\text { 通用 } \\
\text { 航空 }\end{array}$ & 概况 & 产业格局 & 服务支撑体系 & 重点项目 \\
\hline \multirow{10}{*}{$\begin{array}{l}\text { 美国 } \\
\text { 威奇 } \\
\text { 塔机 } \\
\text { 场 }\end{array}$} & \multirow{10}{*}{$\begin{array}{l}\text { 是世界上最大的 } \\
\text { 航空训练机场。 } \\
\text { 供专业技术培 } \\
\text { 训, 医疗, 和外 } \\
\text { 地人员, 飞行员 } \\
\text { 培训, 军事, 其 } \\
\text { 他国防部机关各 } \\
\text { 部门平民和外国 } \\
\text { 公民。威奇托福 } \\
\text { 尔斯市机场跑道 } \\
\text { 下的联合民事和 } \\
\text { 军事安排 }\end{array}$} & \multirow{4}{*}{$\begin{array}{c}\text { 毫克比奇: 研发中心、组装基地、 } \\
\text { 试飞跑道、培训中心、服务中心; } \\
\text { 维修中心、配套厂商生产基地; 主 } \\
\text { 要产品: 公务机 }\end{array}$} & \multirow{5}{*}{$\begin{array}{l}\text { 龙头企业主要方向: 重 } \\
\text { 要部件研发、整机组合 } \\
\text { 特征: 较为垄断 } \\
\text { 合同分包商: 主要方向: } \\
\text { 子系统、系统专用零配 } \\
\text { 件特征: 规模产品类型 } \\
\text { 较多 }\end{array}$} & 国家航空培训中心 \\
\hline & & & & \multirow{2}{*}{$\begin{array}{l}\text { 国家航空研究中心 } \\
(\mathrm{NIAR}) / \text { 技术保障 }\end{array}$} \\
\hline & & & & \\
\hline & & & & \multirow{2}{*}{$\begin{array}{l}\text { 美中制造技术中心 } \\
\text { (AMTC) / 企业竞争 } \\
\text { 保障 }\end{array}$} \\
\hline & & \multirow[t]{2}{*}{ 塞纳斯: 以制造小型通用飞机为主。 } & & \\
\hline & & & & \multirow{2}{*}{$\begin{array}{c}\text { 威奇塔科技公司 } \\
\text { (基金)/产业化保 } \\
\text { 障 }\end{array}$} \\
\hline & & \multirow{3}{*}{$\begin{array}{l}\text { 庞巴迪: 从事宇航产品的设计、开 } \\
\text { 发制造和市场销售; 庞巴迪的所有 } \\
\text { 飞机都在这里的庞巴迪飞行中心进 } \\
\text { 行试飞。 }\end{array}$} & & \\
\hline & & & & \multirow{3}{*}{$\begin{array}{l}\text { 塞奇威克自由贸易 } \\
\text { 区 }\end{array}$} \\
\hline & & & \multirow{2}{*}{$\begin{array}{c}\text { 供应商: 主要方向: 基 } \\
\text { 本零件、组件、固定设 } \\
\text { 备、材料 } \\
\text { 特征: 以小型企业为主 }\end{array}$} & \\
\hline & & $\begin{array}{l}\text { 斯普利特: 全球最大的民用飞机零 } \\
\text { 配件独立供应商、核心产品包括机 } \\
\text { 身、外挂架、引擎机舱和机翼部件; } \\
\text { 零件、保养、维修大修以及机队支 } \\
\text { 持服务。 }\end{array}$ & & \\
\hline \multirow[t]{5}{*}{$\begin{array}{l}\text { 项目 } \\
\text { 借鉴 }\end{array}$} & \multicolumn{4}{|c|}{$\begin{array}{l}\text { 以四大飞机龙头制造业为支撑，在市域西南部和东部形成飞机制造产业带 } \\
\text { (1)龙头带动: 以龙头制造企业作为产业发展战略核心。 }\end{array}$} \\
\hline & \multicolumn{4}{|c|}{ (2)全行业链: 构筑包含制造、运营、培训、维护、文化在内的通航全产业链。 } \\
\hline & \multicolumn{4}{|c|}{ ３集群衍生：依托通航配套产业向关联产业延伸，打造多元化产业集群。 } \\
\hline & (4)服务支撑: & \multirow{2}{*}{\multicolumn{3}{|c|}{$\begin{array}{l}\text { 构建服务业、制造业互动提升的发展平台。 } \\
\text { 加大与周边航空园区的基础设施、招商等各类资源共享。 }\end{array}$}} \\
\hline & & & & \\
\hline
\end{tabular}


表二 加拿大温哥华港机场

\begin{tabular}{|c|c|c|c|}
\hline 通用航空 & $\begin{array}{l}\text { 概况 } \\
\end{array}$ & 产业格局 & 服务支撑体系 \\
\hline $\begin{array}{l}\text { 加拿大温 } \\
\text { 哥华港机 } \\
\text { 场 }\end{array}$ & $\begin{array}{l}\text { 温哥华港机场 } \\
\text { (Vancouver } \\
\text { Harbour Flight } \\
\text { Centre) 位于温哥 } \\
\text { 华市中心, 在温哥 } \\
\text { 华港湾国际会展中 } \\
\text { 心西侧, 是水上飞 } \\
\text { 机的专用机场。 }\end{array}$ & $\begin{array}{l}\text { 水上飞机是温哥华的特色旅游项目之一, } \\
\text { 游客可以体验乘坐水上飞机所带来的刺激与 } \\
\text { 快乐。一般只飞临近城市之间的航线。乘客从 } \\
\text { 这里登机, 可飞往温哥华岛等海湾内各小岛, } \\
\text { 也可飞往附近的美国西雅图。另外还可到达的 } \\
\text { 城市地区有惠斯勒 (Whistler)、纳奈莫 } \\
\text { (Nanaimo)、温哥华国际机场 (YVR) 等。 }\end{array}$ & $\begin{array}{c}\text { 水上机场码头 } \\
\text { 国际会展中心 } \\
\text { 水上机场控制塔 } \\
\text { 加拿大公共活动中心 }\end{array}$ \\
\hline 项目借鉴 & \multicolumn{3}{|c|}{$\begin{array}{l}\text { (1)临近温哥华市中心，优越的地理区位条件，有利于吸引市民及游客。 } \\
\text { (2)具有地区特色，水上飞机是温哥华的特色旅游项目之一。 } \\
\text { (3)周边配套设施完善，拥有加拿大唯一的一个专门为水上机场设置的控制塔。 }\end{array}$} \\
\hline
\end{tabular}

\section{3 沈阳通航小镇产业基地规划}

\section{1沈阳通用航空产业基地定位}

以通航特色小镇为依托，打造四个基地：国家通用航空产业综合示范基地、无人机研发 生产检测试飞基地、军民融合科研成果转化基地、特色户外运动观光体验基地。

建设成为以通用航空为核心的产业基地, 以生态环境优美为特色的宜居城镇, 以山水文 脉为灵魂的养生度假基地。以通航产业为支撑, 与运动休闲、观光体验相融合, 打造成为生 态型、一、二、三产业融合发展的国家级通航特色小镇，成为县域经济的支柱。

规划区遵循 “航空+旅游” 的规划理念。打造一条以 “航” 带 “游”，以“游” 兴 “产”、 以“产” 养 “农” 的特色发展之路。以 “航” 带 “游”，依托财湖景区, 以航空旅游为特色, 推进生态旅游产业发展。以“游” 兴 “产”, 以旅游带动一、二产业发展, 集休闲农业、乡 村旅游、优质农产品产销为一体, 实现一、二、三产业融合。以 “产” 养 “农”, 大力发展 高效农业，打造示范田，引进经济作物，多渠道转移农村劳动力，提升农民就业。

通过发展通航文化、会展、旅游、休闲、体育等配套产业, 带动周边景观农业、餐饮、 民宿等快速发展, 完成宜工则工、宜农则农、宜商则商的产业飞跃

\section{2沈阳通用航空产业发展规划}

\subsection{1空间布局}

沈阳通用航空产业基地规划面积约为68平方公里，根据产业基地的功能分布，将其分为 五大功能板块: 通航核心产业板块、综合配套板块、科研教育板块、生态涵养板块和休闲体 育旅游板块。

(1) 通航核心产业板块。位于规划区核心区域, 紧邻财湖水库东岸, 西至203国道。该 板块包括通航机场、通航产业孵化基地、无人机产业园、运营基地、有人机生产制造组装产 业园、航材保税仓以及部分配套商业设施。

（2）综合配套板块。位于规划区东北部，203国道以东、通航一路以北、沈康高速以西 的区域, 是通航核心产业板块的配套区域。该板块包括通航交通枢纽、通航材料产业园、杏 林学院以及配套综合商业。 
(3) 科研教育板块。位于规划区东南部, 203国道以东、通航一路以南、沈康高速以西 的区域, 以科研、教育和生产为片区主要功能。该板块包括通航技术学院和大量的工业园。

（4）生态涵养板块。位于规划区北部的大部分区域，在此区域中，利用自然条件及生态 环境优势，在邻近财湖水库处规划财湖湿地公园，建设生态保护设施和湿地观光设施。

（5）休闲体育旅游板块。位于规划区西南部，围绕财湖水库和石砬子水库布置，以休闲 旅游、体育运动为主要功能。该板块包括飞行营地、航空主题公园、激光水幕影视城、生态 果园（中草药园）、国际赛马俱乐部、国际赛车俱乐部等。

\subsection{2用地规划}

规划总用地面积为6825.38公顷，其中城市建设用地面积为1775.64公顷。规划城市建设用 地由公共管理与公共服务设施用地、商业服务业设施用地、工业用地、道路与交通设施用地、 公用设施用地、绿地与广场用地、旅游用地构成。非建设用地面积为4412.67公顷，由水域和 农林用地构成。用地结构中还包含公路用地、飞行营地、特色户外休闲体育用地、生态果园 和中草药园、芦苇荡和荷花园、机场净空及预留用地。（如图2）

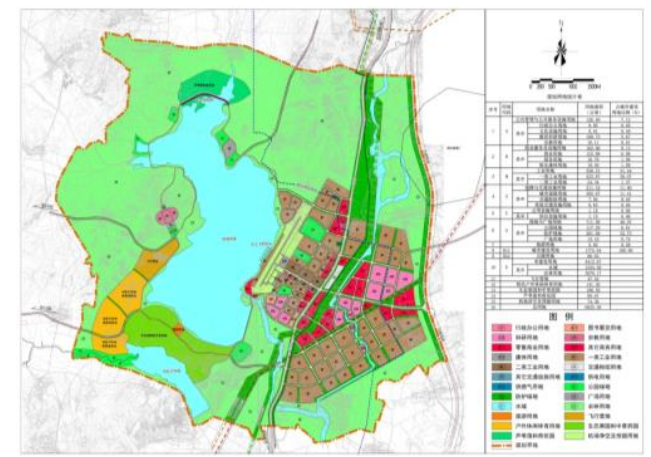

图2 用地规划图 来源: 沈阳城乡规划设计研究院

\subsection{3道路交通}

对外交通: 规划区主要对外交通通道为203国道，向北连接法库县城，向南连接沈阳市区。 另有通航一路向东与沈康高速相连。规划一条城际铁路穿越通航产业基地, 并在规划区中心 区新建一处城际铁路站点, 占地7.94公顷, 加强规划区的对外交通联系, 解决规划区客运出 行及公交衔接等问题。除交通设施外, 同时建设航油站、内部汽油加油站、维修站等配套功 能。道路系统: 路网结构基本采用方格网式布局, 道路系统由主干路、次干路、支路三个等 级构成。主干路是道路系统的主骨架, 是满足规划区对外交通联系、规划区内各功能区之间 交通联系的道路系统。规划主干路9条, 包括通航一路、通航三路、通航一街等。通航一路红 线宽度40米, 其余主干路红线宽度30米。次干路是主干路交通的集散系统, 主要用于功能区 内的地方集散交通或兼做主要交通走廊之间的联络线, 直接服务于城市各种用地, 与主干路 一起构成道路网的骨架。规划次干路红线宽度26米。支路是规划区内部的联系道路, 担负干 道交通的集散任务, 服务于局部性地方交通, 其功能主要是把城市各种用地与城市干道网连 接起来，将交通流均匀地分散于各个组团内。（如图3）

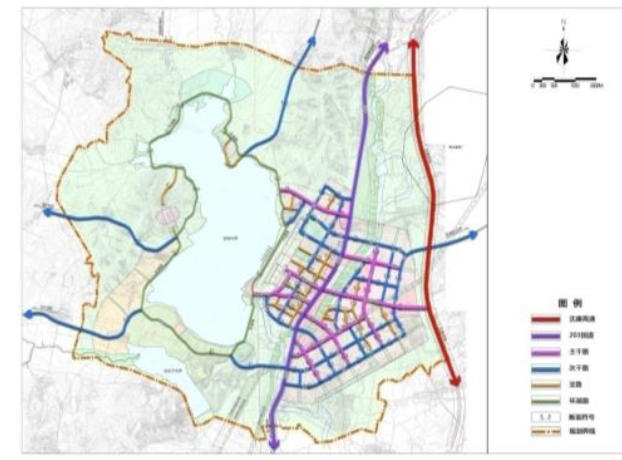

图3 道路交通规划图 来源: 沈阳城乡规划设计研究院 


\subsection{4景观系统}

通过有机合理的组织绿化, 规划形成 “一环两轴, 双心多节点” 的景观格局。一环: 环 湖景观带, 依托环湖路, 将财湖周边各景观节点有序串联。两轴: 道路景观轴和滨河景观轴。 依托通航一路, 形成连接高速公路、交通枢纽、通航机场以及水上飞机码头的道路景观轴线; 依托贯穿南北的水系及防护绿地, 打造良好的带状滨河生态景观轴线。双心: 财宫和通航交 通枢纽。两处标志性景观核心隔湖相望, 形成对景。多节点: 包括航空主题公园、财湖湿地 公园、水幕影视城、生态果园等，丰富城市的景观绿化系统。（如图4）

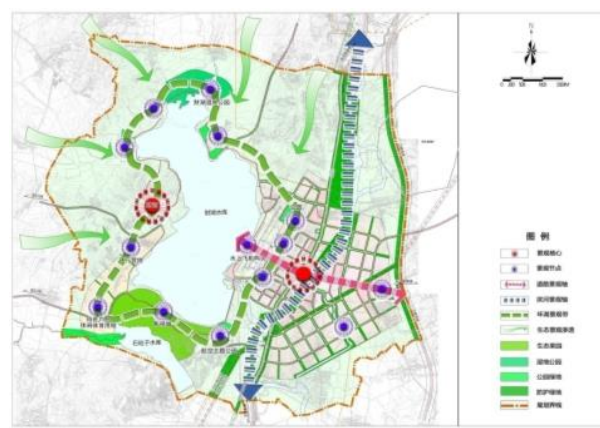

图4 景观规划图 来源: 沈阳城乡规划设计研究院

\section{3沈阳通用航空产业发展规划策略}

从产业上游来看, 通用航空产业链条长，通航产业的发展将带动上下游数十个行业，产 业技术附加值高、资金密集度高, 能够带动国民经济上一个新台阶。从产业下游来看, 通用 航空用途广泛、形态多元，兼具生产工具属性和消费品属性，同时服务于国民经济一、二、 三产业，可以满足我国不同发展水平区域和未来数十年经济社会发展的需要。

1 , 通用航空产业的发展将直接催生航空领域科技创新。2, 通用航空产业还将有力促进 地区济结构转型升级, 拉动航空制造业向高端化发展。3, 通用航空服务于国民经济三次产业 4, 通用航空对国民经济第一、二产业的服务主要是提升了原有作业的效率5, 通用航空的应 用开发了新的市场商业形态, 将许多原本不存在的市场和商业模式带入人们的视野。6, 通用 航空的蓬勃发展还带动了传统行业与通用航空之间、传统行业之间的融合。

基于通用航空上下游产业链, 围绕通用航空机场核心基地业态，通航产业基地可以拓展 不同层次的通航相关业态，形成 “核心基地服务区”、“核心基地+生产区”、“核心基地 +生产区+服务区”、“核心基地+服务区+商贸区+生产区”等不同发展模式。

随着通航产业进入快速发展通道, 沈阳通用航空产业基地有必要打造完善的通航产业链, 由上游研发、制造产业, 保障通航运营的中游保障支持产业和下游市场开发产业所构成, 三 个产业的有机结合形成 “核心基地+服务区+商贸区+生产区” 的全产业链、全价值链模式。

\section{4. 结论}

产业基地的投资建设不但可以带动就业、创造税收、提升居民的收入，进而促进当地经 济、社会的发展, 同时以基地为平台带动通航全产业链的聚集, 以及相关产业如酒店、旅游、 高新科技、房地产、金融等产业的发展。本文以沈阳通航产业基地规划为研究对象, 分析对 比国内外通航产业发展现状以及优秀案例, 以此为研究基础, 综合评价沈阳通航产业基地的 各方面条件要素, 确定通航产业基地的未来发展方向, 并提出通用航空产业的发展理念、发 展模式以及发展策略。 


\section{1 “航空+旅游” 的发展理念}

生态环境是经济社会发展与文明兴衰的基本载体。经济社会发展必须建立在资源得到高 效循环利用, 生态环境受到严格保护的基础上。对于山水相依、绿景环绕的风水宝地, 遵循 “航空+旅游” 的发展理念, 避免大规模的城镇建设对生态格局的影响，因地制宜的开发旅游 产业，充分利用自然资源，同时与通航产业结合，打造独一无二的绿色生态产业基地。

\section{2 “核心基地+服务区+商贸区+生产区”的发展模式}

通用航空是国家战略性新兴产业, 我国通用航空产业处于起步阶段, 在通航产业发展过 程中, 需要结合我国国情, 落实通航发展政策, 培育通航市场, 促进通航制造与运营服务协 调发展。采用 “核心基地+服务区+商贸区+生产区” 的发展模式，产业基地的投资建设不但 可以带动就业、创造税收、提升居民的收入，进而促进当地经济、社会的发展，同时以产业 基地为平台带动通航全产业链的聚集, 以及相关产业如酒店、旅游、高新科技、房地产、金 融等产业的发展。

\section{3 “产业规划与城镇规划相结合” 的发展策略}

产业规划与城镇规划在发展过程中是一种双向互促关系, 互为先导。城镇规划引导产业 的空间布局,影响着产业发展的方向，并进而对产业规划形成较大的推动作用。产业发展引起 城镇功能的变化, 对城镇规划提出新的要求, 促进城镇功能布局的调整。实行 “产业规划与 城镇规划相结合” 的发展策略, 将通用航空产业纳入到城镇整体规划布局中, 从全域角度考 虑产业定位与各项设施配套，使产业发展和城镇建设达到良好融合。

\section{References}

[1] Kong Mingde. Research on the construction of Shenyang General Aviation Industry Base[ [J]. Shenyang Cadre Journal, 2011(1): 55-56.

[2] Gaoqiming, Jingan. China's general aviation industry development characteristics, key issues and mode selection[ [J]. Economic aspect, 2013(4): 98-102.

[3] Lilian. Analysis on the development path of general aviation industry in every province and province of China[ [J]. Bohai Rim Economic Outlook, 2015(11): 21-25.

[4] Zhangjun,jingmen's Research on the Development of General Aviation Industry Chain[J]. Hubei Agricultural Mechanization, 2015(5): 6-7.

[5] Gao Linzhao. Problems and countermeasures for the development of general aviation in China[ [J]. Journal of Zhengzhou Institute of Aeronautical Industry Management, 2016, 34(6): 13-16. 